\title{
Modelling of a thermally activated building system (TABS) combined with free-hanging acoustic ceiling units using computational fluid dynamics (CFD)
}

\author{
Lacarte, Luis Marcos Domínguez ; Fan, Jianhua
}

Published in:

Building Simulation

Link to article, DOI:

10.1007/s12273-017-0392-x

Publication date:

2018

Document Version

Peer reviewed version

Link back to DTU Orbit

Citation (APA):

Lacarte, L. M. D., \& Fan, J. (2018). Modelling of a thermally activated building system (TABS) combined with free-hanging acoustic ceiling units using computational fluid dynamics (CFD). Building Simulation, 11(2), 315324. https://doi.org/10.1007/s12273-017-0392-x

\section{General rights}

Copyright and moral rights for the publications made accessible in the public portal are retained by the authors and/or other copyright owners and it is a condition of accessing publications that users recognise and abide by the legal requirements associated with these rights.

- Users may download and print one copy of any publication from the public portal for the purpose of private study or research.

- You may not further distribute the material or use it for any profit-making activity or commercial gain

- You may freely distribute the URL identifying the publication in the public portal 


\title{
Modelling of a Thermally Activated Building System (TABS) combined with free-hanging acoustic ceiling units using Computational fluid dynamics (CFD)
}

\author{
L. Marcos Domínguez Lacarte*, Jianhua Fan ${ }^{1}$ \\ 1 Department of Civil Engineering, Technical University of Denmark, Brovej 118, DK-2800 Kgs. Lyngby, \\ Denmark
}

\section{Abstract}

Thermally Activated Building Systems (TABS) have proven to be an energy-efficient solution to achieve optimal indoor thermal environment in buildings. This solution uses the building mass to store heat and by means of water pipes embedded in the concrete slabs adjust the temperature in the premises. The active surfaces of TABS need to be as exposed as possible, but exposing bare concrete surfaces has a negative impact on the acoustic quality in the premises. Acoustic solutions capable of providing optimal acoustic comfort while allowing the heat exchange between the TABS and the room are desirable. This study focuses on the influence of two types of free-hanging ceiling absorbers (horizontal and vertical) on the cooling performance of the TABS. Different scenarios are investigated for each type of sound absorber. Computational Fluid Dynamics (CFD) simulations are used to illuminate the nature of the heat exchange between the TABS and the room and the occupants. The simulations are validated by comparison with full scale measurements in laboratory conditions. The study shows that for equivalent sound absorption levels, free-hanging vertical sound absorbers have a lower impact on the heat exchange between the room and the TABS compared to freehanging horizontal sound absorbers. Cold air stagnation between the sound absorber units and the TABS has been identified as the major cause of the cooling performance decrease of the TABS.

Keywords

TABS; thermal environment; sound absorption; cooling capacity; Full-scale measurements; building simulations; Computational Fluid Dynamics

\section{Introduction}

A building's function is to provide a safe and healthy enclosure for people's activities, to protect them from the outdoor environment and to provide optimal levels of comfort. On the other hand, buildings need energy to provide the right indoor environmental conditions. According to the European Environment Agency [1], buildings are responsible for about $40 \%$ of the total energy use in the European Union (EU). Introducing energy savings involves

* Corresponding author. Tel: +45-52807307

Email address: marcosdomin@outlook.com (Luis Marcos Domínguez Lacarte) 
higher costs when the building has already been constructed. For this reason, the integration of energy savings and the use of sustainable energy resources should be a priority from the early stages of the building design. Low temperature heating and high temperature cooling systems (water-based radiant heating and cooling systems in this context) have proven to be an energy efficient solution for conditioning buildings [2]. Thermally Activated Building Systems (TABS) are an example of radiant heating and cooling systems. TABS' main principle is to use the thermal mass of the building to store heat and to activate the building thermal mass by embedding water-carrying pipes in the building structure. The thermal indoor environment is controlled by emitting or removing heat from the indoor space by heated or cooled TABS surfaces, and by adding or extracting heat from the TABS structure by water circulation. Radiant systems and TABS have several advantages, such as benefiting from the low temperature heating and high temperature cooling principle [3], [4], [5], [6], possibility of coupling with renewable heat sources and sinks [7], [8], [9], possibility of transferring peak heating and cooling loads to off-peak hours and peak load reductions [2], [10], [11], [12].

The use of TABS has grown in commercial buildings since the 1990s, first in Central Europe (Germany, Austria, Netherlands, etc.), TABS are now spreading globally. As a matter of fact, modern buildings require effective building systems, and TABS represent a high-potential solution by cooling the slab, thus allowing the room to be cooled by the ceiling and floor. TABS are mostly used in multi-storey buildings, since the thermal exchange occurs both upwards and downwards [13].

However, TABS require large hard surfaces to be exposed, which could have a negative impact on the acoustic quality of indoor spaces [5], [14]. In the case of office spaces, a productivity reduction of $67 \%$ was reported in employees working in noisy spaces [15]. New building standards and certifications are not sufficient, room acoustics is the only category where the performance is worse in new green buildings compared to non-green buildings and is the category with the lowest satisfaction rating [16]. Acoustic solutions that are capable of providing optimal acoustic comfort while allowing the heat exchange between the room and the TABS are desirable. Free-hanging ceiling absorbers can be a solution for addressing acoustic concerns; however, they will affect the cooling performance of TABS when used in combination.

Different authors have studied the effects of sound absorbers on cooling performance of TABS by climate chamber measurements [17], [18], [19], [20], [21], [22], by field measurements [23], [24], [25], [26], and more recently by dynamic building simulations [27], [28], [29], [30], but to the knowledge of these authors a detailed Computational Fluid Dynamics (CFD) analysis of the manner in which the sound absorber units interfere in the heat exchange between the TABS and room was still missing.

This study focuses on the influence of two types of free-hanging ceiling absorbers (horizontal and vertical panels) on the heat exchange between the active surface of the TABS and the room, and the implications this has on the temperature in the room. The manner in which the sound absorber units interfere in the heat exchange between the TABS and room has been investigated by means of CFD simulations.

\section{Methods}


Investigations in this study are based on full-scale measurements, performed under controlled conditions in a test facility that resembles an office room with TABS, and on numerical investigations with the CFD software ANSYS Fluent 16.2.

\subsection{Details of the studied acoustic panels and layout}

Two types of free hanging sound absorber units were tested. These sound absorber units were identified to be compatible with the performance of TABS [31], i.e. by covering the ceiling surface partially, which allows the heat exchange between the TABS and the room through convection and radiation. One type corresponds to horizontal sound absorbers (Figure 1(a)), and the second type corresponds to vertical sound absorbers suspended similar to baffles, (Figure 1(b)). The panels are made of high density glass wool with a thickness of $40 \mathrm{~mm}$ and with dimensions $1160 \times 1000 \mathrm{~mm}$ and $1200 \times 300 \mathrm{~mm}$ for horizontal and vertical panels respectively.
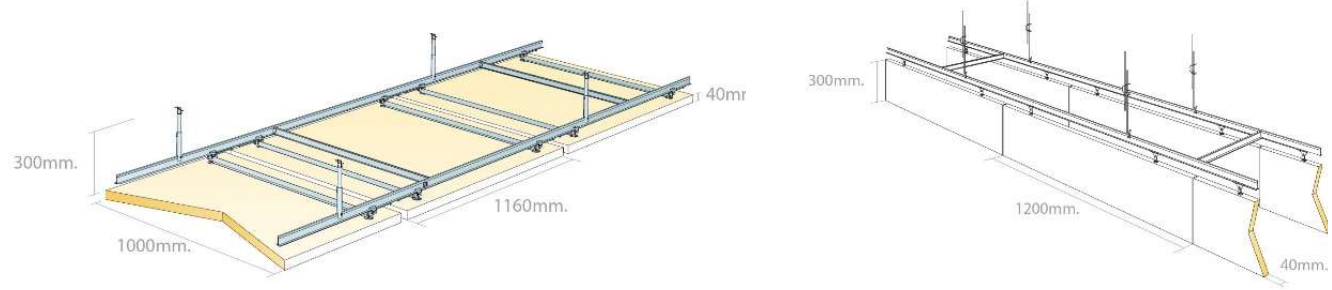

Figure 1: (a) Free-hanging horizontal panels (the left) (b) Free-hanging vertical panels or baffles (the right).

Three scenarios were studied with free-hanging horizontal sound absorbers (see Table 1). In order to allow the heat exchange between the TABS and the room [29], the panels were placed at a distance of $300 \mathrm{~mm}$ from the soffit, aiming for an even distribution along the ceiling area for the following ceiling coverage ratios. Figure 2 shows grid dimensions for horizontal sound absorbers.

\begin{tabular}{ccc}
\hline Scenario & Coverage ratio & Number of horizontal panels \\
\hline 1a & $43 \%$ & 8 \\
2a & $60 \%$ & 11 \\
3a & $80 \%$ & 15 \\
\hline
\end{tabular}

Table 1: Summary of the scenarios with horizontal panels

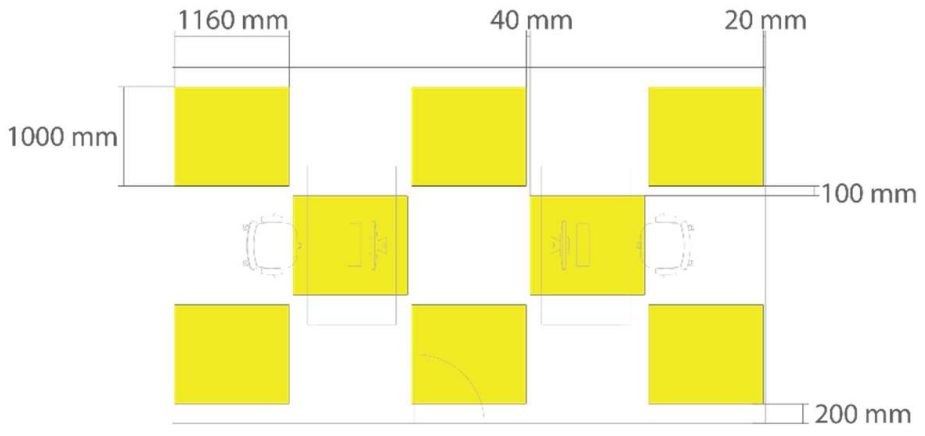


Scenario 1a ( $43 \%$ coverage ratio)

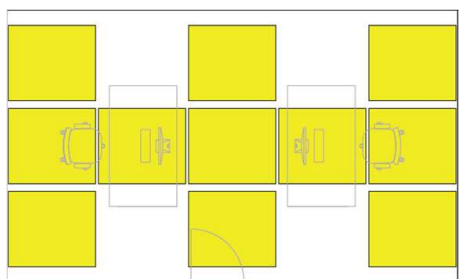

Scenario $2 \mathrm{a}(60 \%$ coverage ratio $) \quad$ Scenario $3 \mathrm{a}(80 \%$ coverage ratio $)$

Figure 2: Grid dimensions and layout for horizontal sound absorbers (80\% ceiling coverage scenario represented)

In the case of the vertical sound absorbers, five scenarios were studied. The panels were also placed at a distance of $300 \mathrm{~mm}$ from the soffit evenly spread along the ceiling area. The scenarios selected were identified as the most reasonable acoustic solutions for offices. For comparison purposes, two additional scenarios were proposed ( $6 \mathrm{~b}$ and $8 \mathrm{~b}$ ) matching the sound absorption achieved with horizontal panels (see Table 2). Sound absorption levels are calculated for each scenario according to [32], this is provided in Equivalent Absorption Area (EAA) in the octave bands $500 \mathrm{~Hz}$ and $1000 \mathrm{~Hz}$. EAA is the equivalent absorption area $\left(\mathrm{m}^{2}\right)$ corresponding to a unit of area of totally absorbent material. Calculation details can be found in [33]. Figure 3 shows grid dimensions for vertical panels.

\begin{tabular}{cccc}
\hline Scenario & $\begin{array}{c}\text { Distance between } \\
\text { baffles }\end{array}$ & $\begin{array}{c}\text { Sound absorption } \\
\text { equivalence to }\end{array}$ & $\begin{array}{c}\text { Number of vertical } \\
\text { baffles }\end{array}$ \\
\hline $4 \mathrm{~b}$ & $400 \mathrm{~mm}$ & & 42 \\
$5 \mathrm{~b}$ & $300 \mathrm{~mm}$ & $1 \mathrm{a}$ & 57 \\
$6 \mathrm{~b}$ & - & $2 \mathrm{a}$ & 78 \\
$7 \mathrm{~b}$ & $200 \mathrm{~mm}$ & & 87 \\
$8 \mathrm{~b}$ & - & $3 \mathrm{a}$ & 105 \\
\hline
\end{tabular}

Table 2: Summary of the scenarios with Vertical Baffles

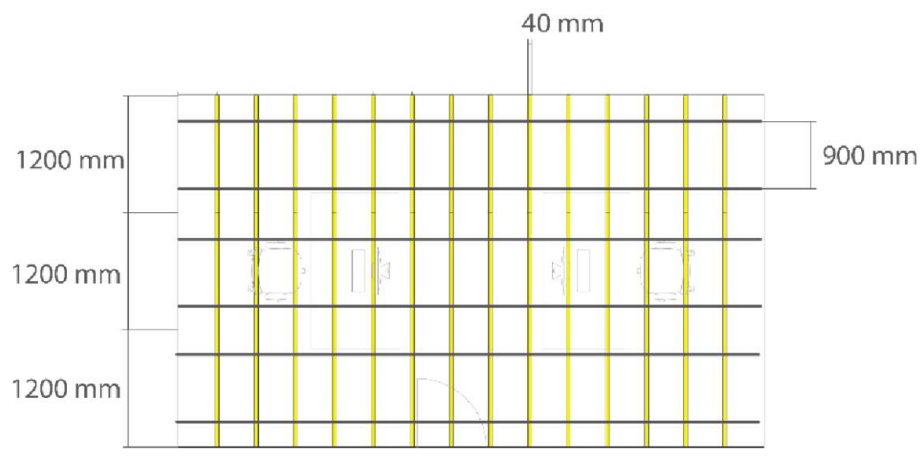

Scenario $4 \mathrm{~b}$ (400 $\mathrm{mm}$ between baffles) 


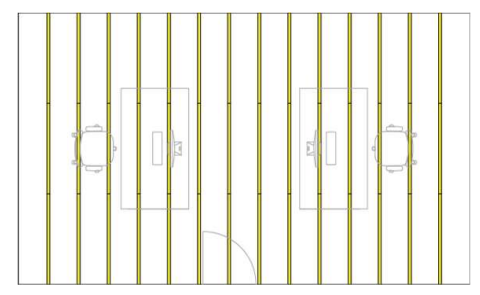

Scenario $5 \mathrm{~b}(300 \mathrm{~mm}$ between baffles)

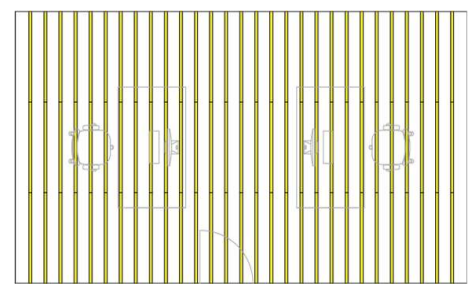

Scenario $7 \mathrm{~b}(200 \mathrm{~mm}$ between baffles)

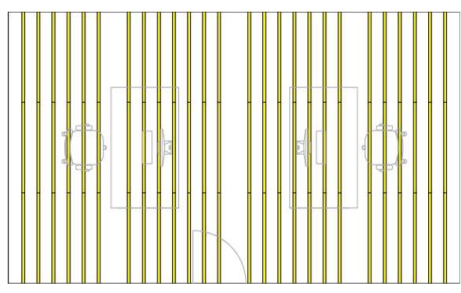

Scenario 6b (comparable sound absorption to scenario $2 \mathrm{a}$ )

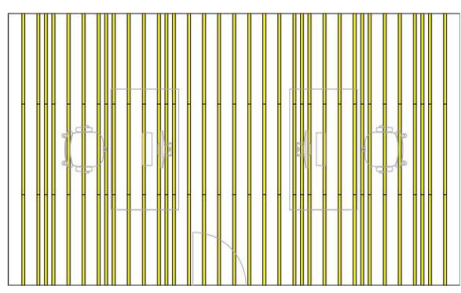

Scenario 8b (comparable sound absorption to scenario $3 \mathrm{a})$

Figure 3: Grid dimensions for vertical panels (Scenario with baffles at $400 \mathrm{~mm}$ represented)

In addition, a case with a bare-ceiling was also studied and used as the reference of the cooling performance of the TABS when there were no sound absorbers (Scenario 9).

\subsection{Full-scale measurement set-up}

Experiments were carried out in a test facility located at the Technical University of Denmark that resembles a two persons' office in a building with TABS. The facility consists of a 21.6 $\mathrm{m}^{2}$ room with a ceiling height of $3.6 \mathrm{~m}$. The floor and ceiling consist of thermo-active concrete decks to attain realistic conditions of a multi-storey building with TABS. The room and the decks are surrounded by a thermal guard, whose temperature is controlled to ensure an equal temperature to that inside the room and hence avoid thermal losses or gains. Figure 4 shows the details of the test facility.

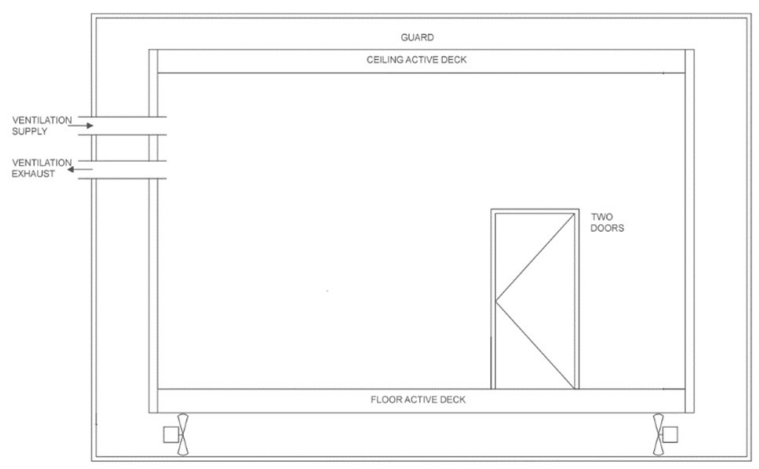

(a)

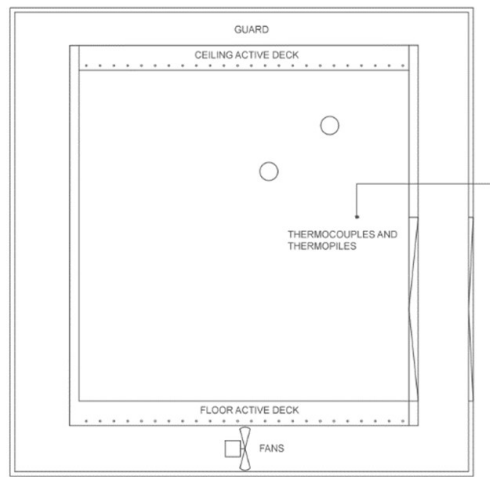

(b)

Figure 4: (a) Descriptive geometry of the test facility (longitudinal section) (b) Descriptive geometry of the test facility (transversal section) 
The room has a ventilation system that is capable of providing airflow at a defined flow rate and temperature. In order to simulate the occupied period of a two-person office room, heat loads were represented by means of two thermal manikins, two computers with monitors, four light bulbs and a heating mat representing the solar heat gains from a window on a summer day in Denmark [34]. Experimental conditions are summarized in Table 3.

\section{Table 3. Summary of the operating conditions during the experiments}

\begin{tabular}{lc}
\hline Constant condition & Value \\
\hline \hline Total heat loads, W/m ${ }^{2}$ & 34.95 \\
Occupants, W & $2 \times 65$ \\
Computer and monitor, W & $2 \times 120$ \\
Lighting, W & $4 \times 50$ \\
Heating mat (window), W & $1 \times 175$ \\
Ventilation supply temperature, ${ }^{\circ} \mathrm{C}$ & 20 \\
Ventilation rate, ACH & 1.35 \\
Water supply temperature decks, ${ }^{\circ} \mathrm{C}$ & 15 \\
Water flow rate (floor/ceiling), $\mathrm{kg} / \mathrm{h}$ & $293 / 283$ \\
\hline
\end{tabular}

The thermal indoor environment in the room was assessed by means of air and operative temperature sensors (thermocouples) as shown in Figure 5. Sensors to assess the thermal comfort of the occupants were mounted at different levels according to the recommendation in ISO 7726 (2012) [35], which were $0.1 \mathrm{~m}, 0.6 \mathrm{~m}, 1.1 \mathrm{~m}$ and $1.7 \mathrm{~m}$. Measurement instruments were calibrated before the experiments. Air, globe, and surface temperature sensors were calibrated within the temperature range of 17 to $34^{\circ} \mathrm{C}$. The sensors were placed inside a polystyrene calibration box in order to limit the effects of airflow and radiation from the surfaces on the sensors, and this box was placed inside the climate chamber. The temperature inside the calibration box (reference temperature) was monitored by a high-accuracy electronic thermometer, which had an accuracy of $\pm 0.04^{\circ} \mathrm{C}$ in the range of 0 to $150^{\circ} \mathrm{C}$. The temperature inside the chamber was adjusted gradually and the reference temperature was monitored. The readings from the sensors were recorded once the temperature in the calibration box was steady and these readings were used to create the calibration curves for the sensors. Other measuring equipment were calibrated by the manufacturers. The air and globe temperatures (globe temperature corresponds to operative temperature at $0.6 \mathrm{~m}$ and at $1.1 \mathrm{~m}$ heights) were measured with thermocouples with an accuracy of $\pm 0.3^{\circ} \mathrm{C}[36]$ 


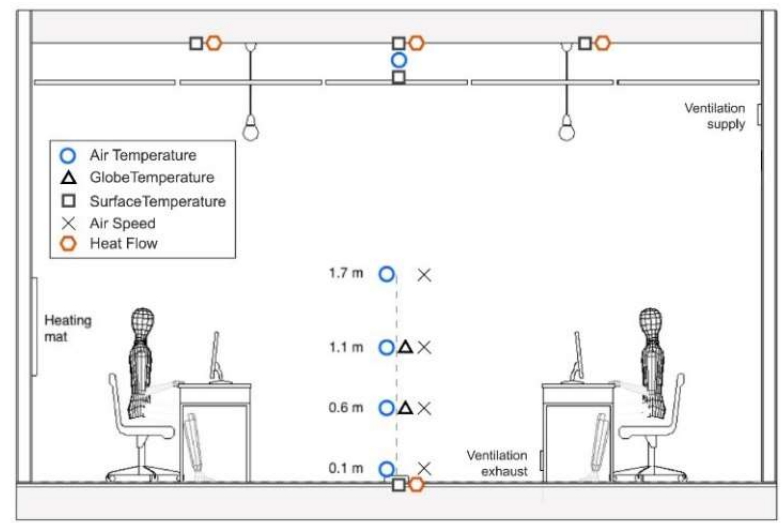

Figure 5: Position of the measurements and heat loads in the room

Measurements were performed under steady-state conditions, and data were obtained once the steady-state conditions were reached.

\subsection{Numerical model}

All the scenarios were modelled with the Computational Fluid Dynamics (CFD) software ANSYS Fluent 16.2. The models represent a simplified geometry of the full-scale facility used during the experiment. These simplifications were made to increase the accuracy of the simulation while reducing the required computing power. Figure 6 illustrates two of the models simulated with the most relevant boundary zones marked in blue.

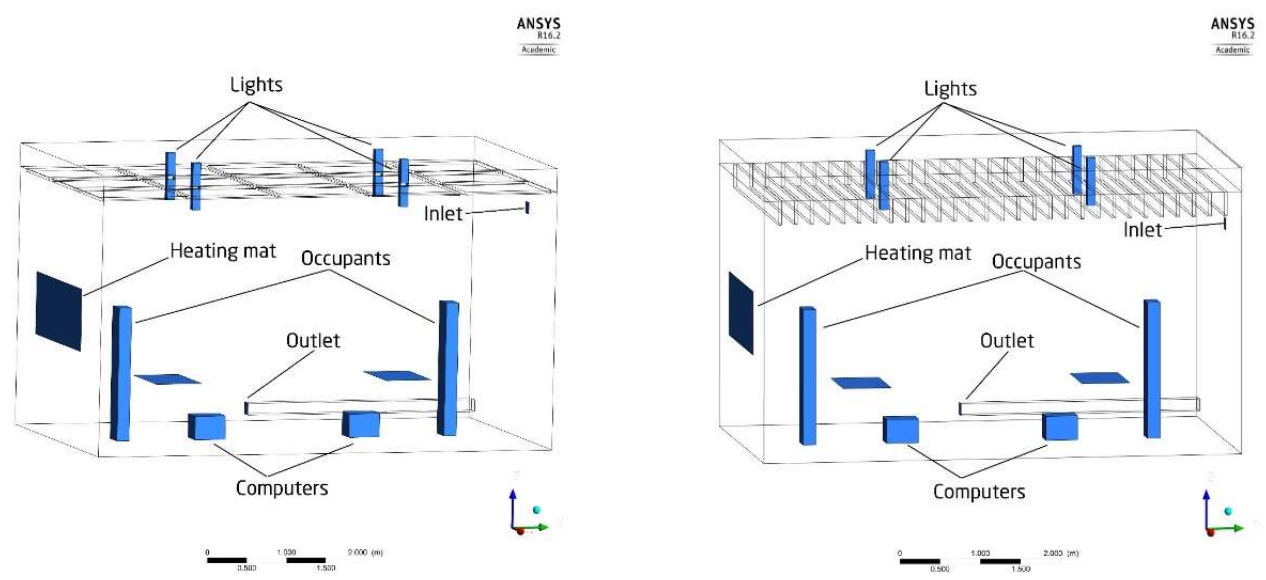

Figure 6: Simplified model of the full-scale test room in ANSYS Fluent. Left: Model for horizontal panels; Right: Model for vertical baffles

The model consists of a solid domain with the acoustic sound absorbers and a fluid domain with the rest of the model. Table 4 shows the properties of the materials used in the CFD simulations.

\begin{tabular}{lcc}
\hline & Air (fluid domain) & Glass Wool(solid domain) \\
\hline \hline Density $\left[\mathrm{Kg} / \mathrm{m}^{3}\right]$ & 1.2 & 123 \\
$\mathrm{Cp}$ (specific heat) $[\mathrm{J} / \mathrm{kg}-\mathrm{K}]$ & 1006.43 & 0.67 \\
\hline
\end{tabular}




\begin{tabular}{lcc}
\hline Thermal conductivity $[\mathrm{W} / \mathrm{m}-\mathrm{K}]$ & 0.0258 & 0.03 \\
Viscosity $[\mathrm{W} / \mathrm{m}-\mathrm{s}]$ & $1.813 \times 10^{-5}$ & - \\
Thermal expansion coefficient $[1 / \mathrm{K}]$ & 0.0034 & - \\
\hline
\end{tabular}

Table 4: Properties of materials used in CFD simulations

The heat loads used in the full-scale measurements have been applied as a heat flux to the respective boundary zones in the CFD models. The ventilation system has been modelled by creating a velocity-inlet boundary zone for the ventilation supply duct and an outflow boundary zone for the exhaust. The position and the area of the ducts have been modelled according to the existing system in the test facility. The ventilation flow rate is specified as a constant velocity magnitude in the area of the velocity-inlet boundary zone. An average of the inlet air temperature measured during the full-scale measurements for each scenario is used as input in the model. The enclosing walls are considered adiabatic to simulate the presence of the thermal guard in the test facility. The heat removed by the TABS according to the fullscale measurements is applied as a heat flux for the entire surface of the ceiling and the floor.

\section{Meshing process}

In order to achieve a well-structured and high quality mesh, the model has been decomposed in sweepable bodies (Figure 7). This decomposition into sweepable bodies allows to create an hexahedron mesh. This type of mesh is reputed to be more efficient, requiring less computation power and yielding more accurate results than e.g. unstructured tethraedral meshes [37].

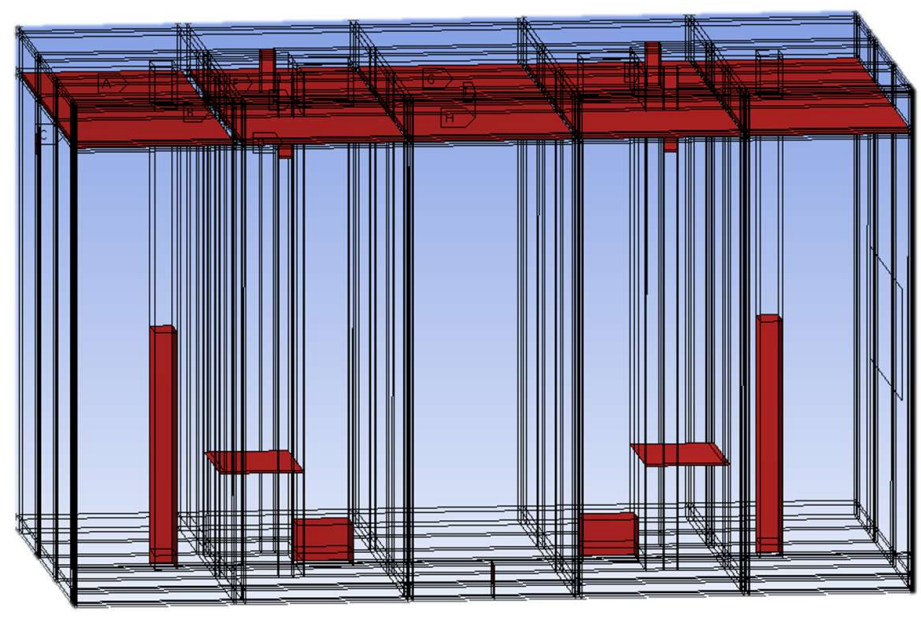

\section{Figure 7: Model decomposition prepared for hexahedron mesh}

The number of mesh elements ranges from 1,521,447 to 2,002,160 cells depending on the scenario simulated. Global mesh size was set to $0,04 \mathrm{~m}$. with refined local element size 0,02 $\mathrm{m}$. in the inlet and outlet areas and mesh inflation close to the boundaries. Investigation of the influence of grid density on the final solution concluded that the solutions were gridindependent. The scenario with bare-ceiling is the one with lower amount of cells. The metric used to evaluate the quality of the mesh is the skeweness. This latter determines how close to ideal (i.e., equilateral or equiangular) the shape of a cell is and is scaled from 0 (Excellent) to 
1 (Unacceptable) [38]. The average value of mesh skeweness in the models ranges from 0.03 to 0.08 depending on the scenario, and the maximum cell skewness varies from 0.7 to 0.76 .

\section{Results and Discussion}

\subsection{Horizontal sound absorbers}

As a consequence of the presence of the sound absorbers, the heat exchange between the TABS and the room is affected and the air temperature in the occupied space of the room (measured at $0.6 \mathrm{~m}$ ) increases. As it can be observed from Figure 8, according to the full-scale measurements, this increase is of 1.5 and $1.6 \mathrm{~K}$ for $60 \%$ and $80 \%$ coverage respectively. CFD simulations show similar temperature increase compared to the reference case, though the model predicts higher temperatures. The difference between the CFD calculated air temperature and the measured air temperature could be due to ....

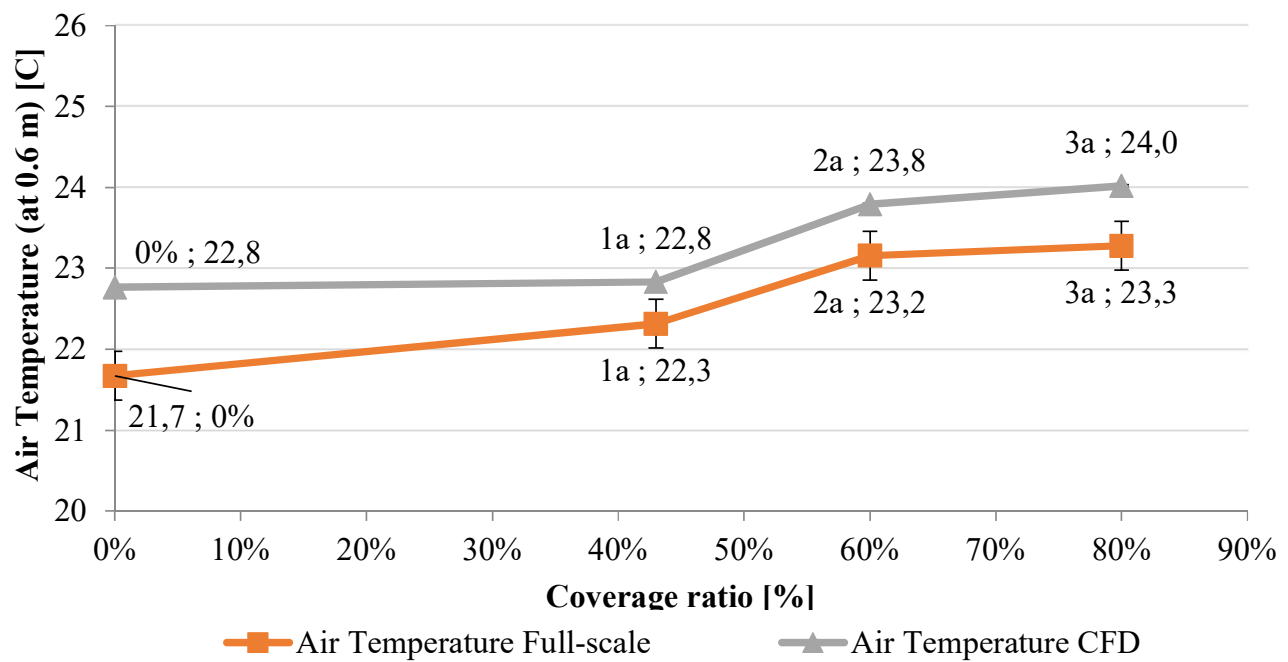

Figure 8: Air temperature comparison between full-scale measurement and CFD simulations with horizontal panels, measured at $0.6 \mathrm{~m}$ from the floor

Figure 9 shows a comparison of the measured air temperatures registered along a vertical pole from the floor to the ceiling in the centre of the room. As it can be seen, the temperature measured in the space between the soffit and the panels $(3.45 \mathrm{~m})$ remains similar for all scenarios, proving the heat exchange impediment created by the panels. The temperature difference between the plenum space and the occupied space of the room is of $0.6 \mathrm{~K}$ for $43 \%$ coverage, $1.4 \mathrm{~K}$ for $60 \%$ coverage and $1.8 \mathrm{~K}$ for $80 \%$ coverage, whereas this difference is of $0.2 \mathrm{~K}$ for the bare-ceiling measured at the same points. This temperature stratification in the plenum also affects the surface temperature of the ceiling concrete deck, this latter is lower for higher coverage ratios. 


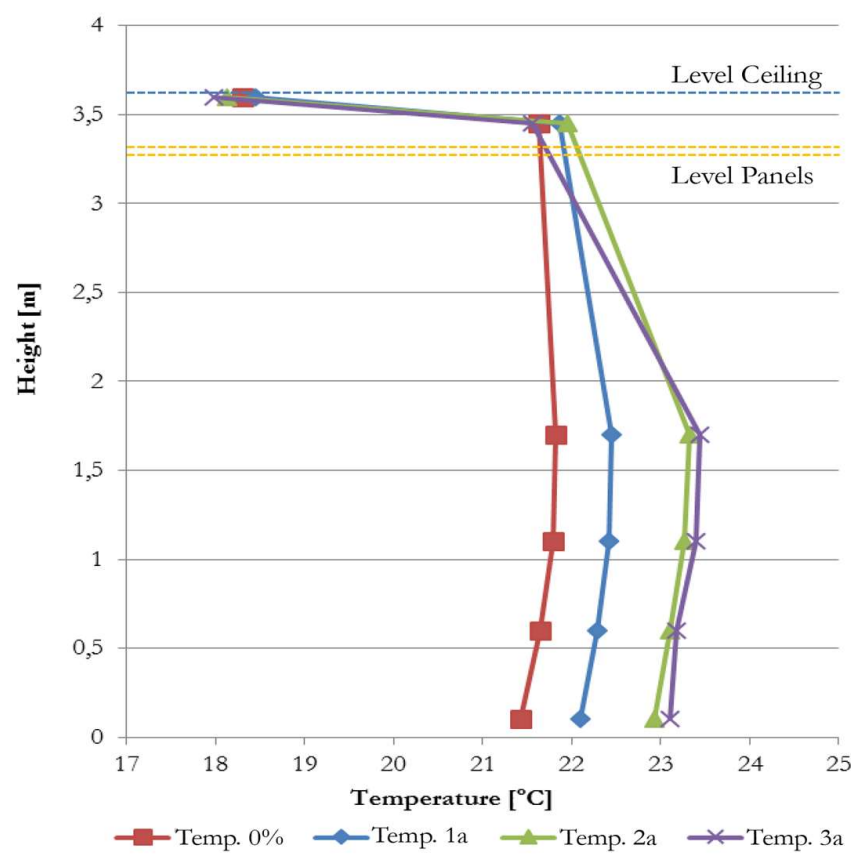

Figure 9: Comparison of measured air temperature at different heights for each scenario with horizontal panels (full-scale measurements)

Figure 10 shows a comparison of the simulated air temperature distribution along the longitudinal section of the room for the scenarios with horizontal panels. In the reference case, the air temperature remains uniform indicating a good mixing of the air in the room. The hot air removed from the occupants rises to the ceiling, then the air is cooled down as it gets in contact with the soffit and then drops again to the occupied area mainly from the right-hand side of the room. The temperature in the room is found to be consistently uniform at $22.8^{\circ} \mathrm{C}$.

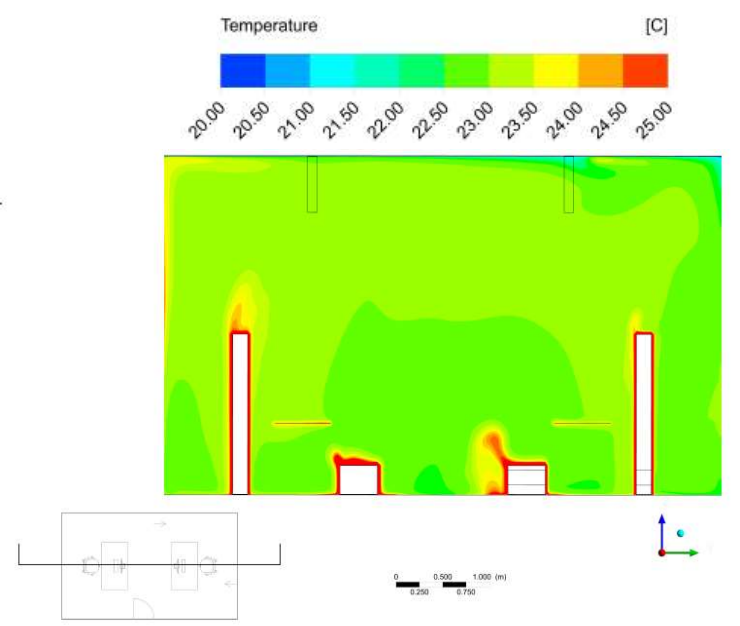

Reference case

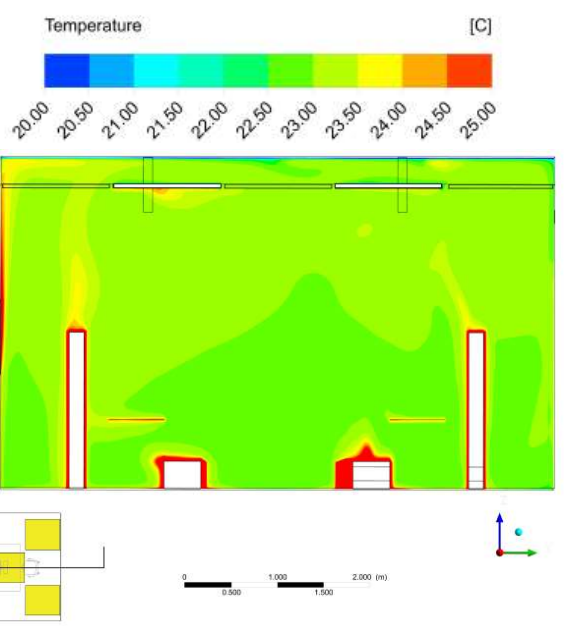

$43 \%$ coverage 


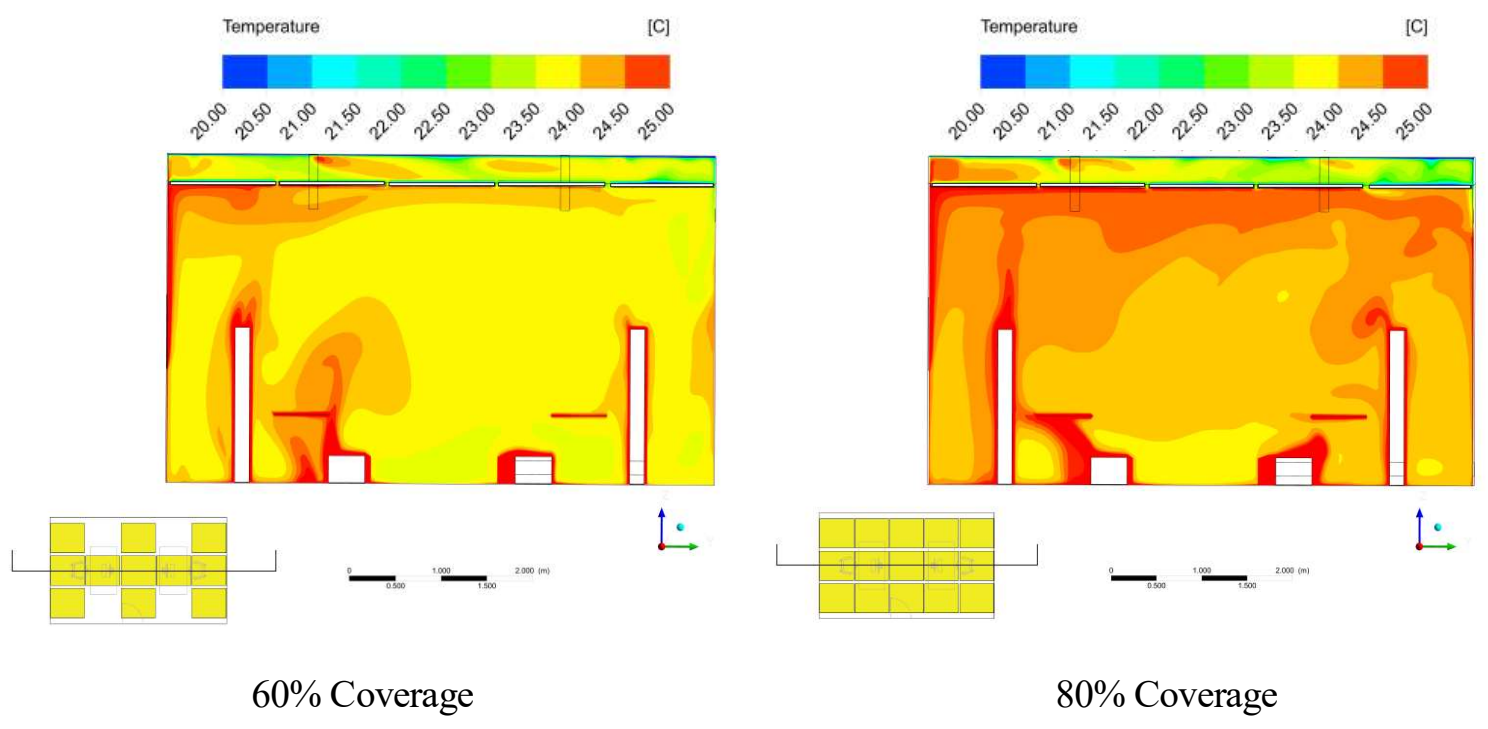

Figure 10: Comparison of air temperature distribution for different coverage ratios with horizontal panels according to CFD simulations

The temperature in the occupied zone increases with the increase of ceiling coverage ratio. The horizontal panels act as a shield on the heat exchange between the occupants and heat loads in the room and the TABS, this is especially noticeable in the scenarios with 60 and $80 \%$ coverage. In these scenarios a hot air layer is created under the panels keeping the hot air from accessing the thermal mass. The average temperature of the air volume above and below the panels has been calculated, showing negligible temperature differences for the case with $43 \%$ coverage, $0.2 \mathrm{~K}$ for the case with $60 \%$ and $0.5 \mathrm{~K}$ for the case with $80 \%$ coverage.

\subsection{Vertical sound absorbers}

In the case of the vertical sound absorbers, as shown in Figure 11, the air temperature at $0.6 \mathrm{~m}$ from the floor level increases $0.4 \mathrm{~K}$ for the scenario with vertical sound absorbers at $400 \mathrm{~mm}$ (4b), $0.5 \mathrm{~K}$ at $300 \mathrm{~mm}(5 \mathrm{~b})$ and $0.8 \mathrm{~K}$ at $200 \mathrm{~mm}(7 \mathrm{~b})$ respectively compared to the reference scenario. 


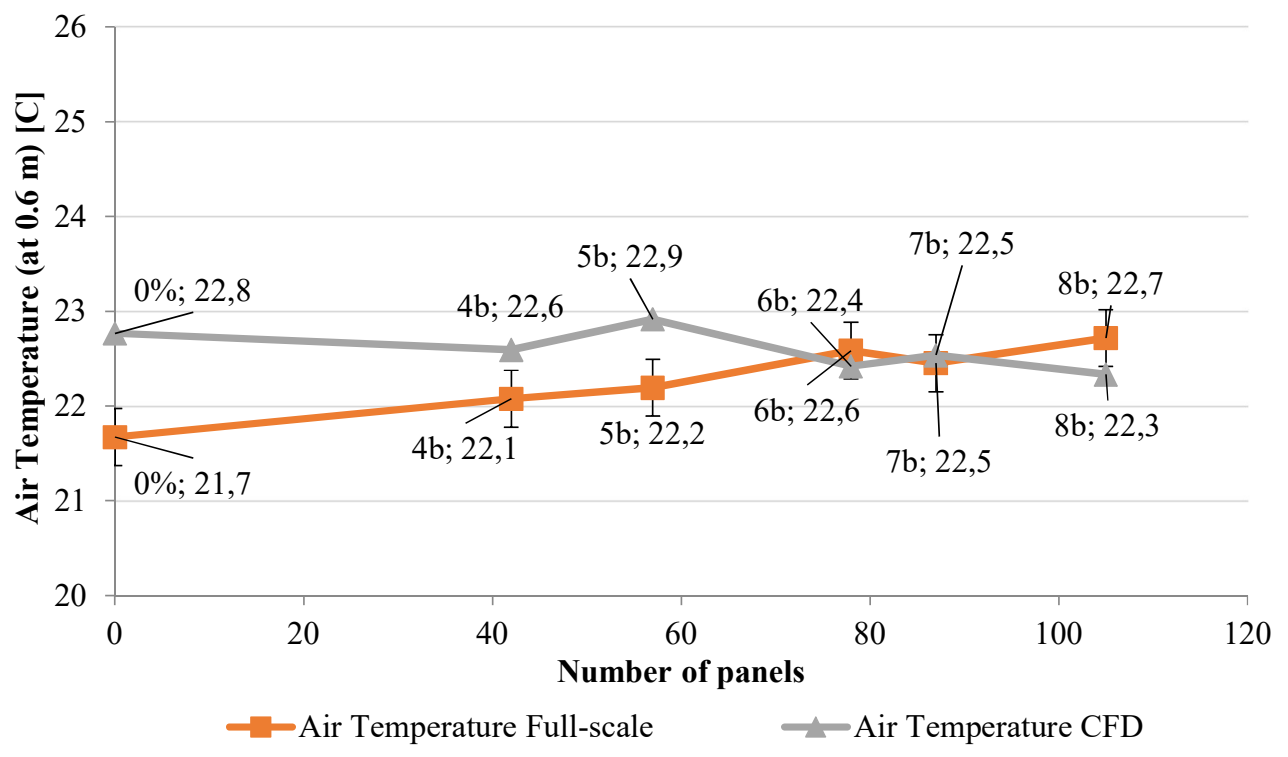

Figure 11: Air temperature comparison between full-scale measurement and CFD simulations with vertical panels, measured at $0.6 \mathrm{~m}$ from the floor

Figure 12 shows a comparison of the measured air temperature distribution along a vertical pole in the centre of the room for the scenarios with vertical panels. As it can be observed, differences between the occupied zone of the room (measured at $0.6 \mathrm{~m}$ ) and the plenum are kept in the range of 0.4 to $0.7 \mathrm{~K}$ for the scenarios with baffles in comparison with the $0.2 \mathrm{~K}$ difference found in the reference case with the bare-ceiling. This temperature difference does not increase with the increase of ceiling coverage ratio. The temperature of the ceiling surface rises with the increase of the number of panels, and hence evolves in the same manner as the temperature increase in the occupied zone. The ceiling surface temperature remains constant for all the scenarios. 


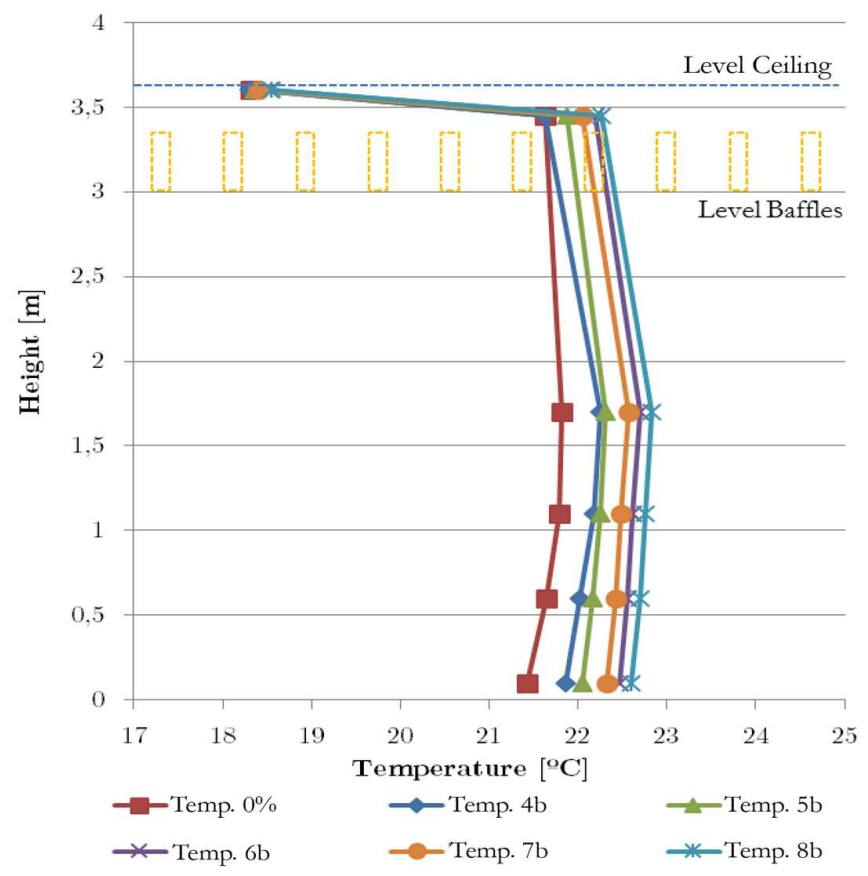

Figure 12: Comparison of measured air temperature at different heights for each scenario with vertical panels (full-scale measurements)

From the CFD analysis presented in Figure 13 it can be observed that the air temperature in the room of the reference case is distributed homogeneously, following the same temperature pattern as that found on the bare-ceiling scenario. The average temperature of the air above the baffles has been found to be $0.1 \mathrm{~K}$ higher than that of the space below for all the scenarios, regardless of the coverage ratio. It can also be observed that the heat removed from the occupants accesses directly the soffit, without being disturbed by the presence of the panels regardless of the ceiling coverage ratio.

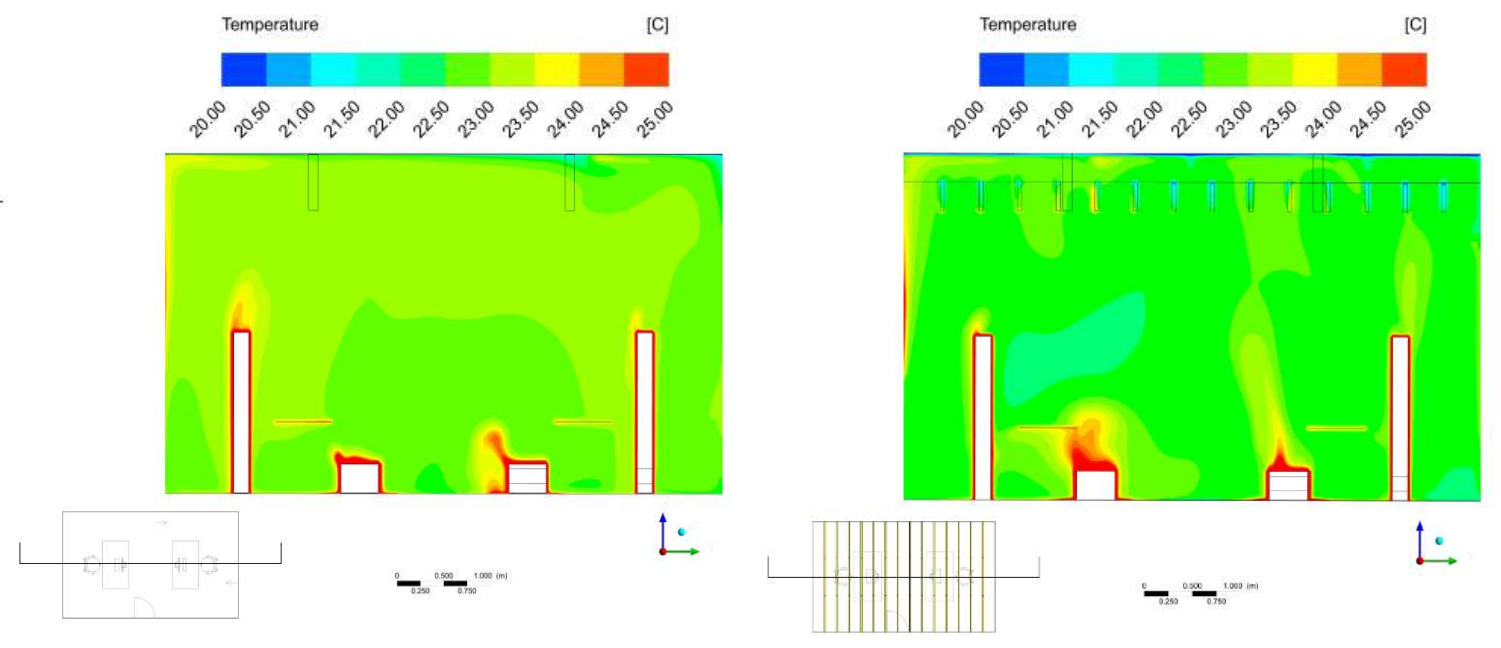




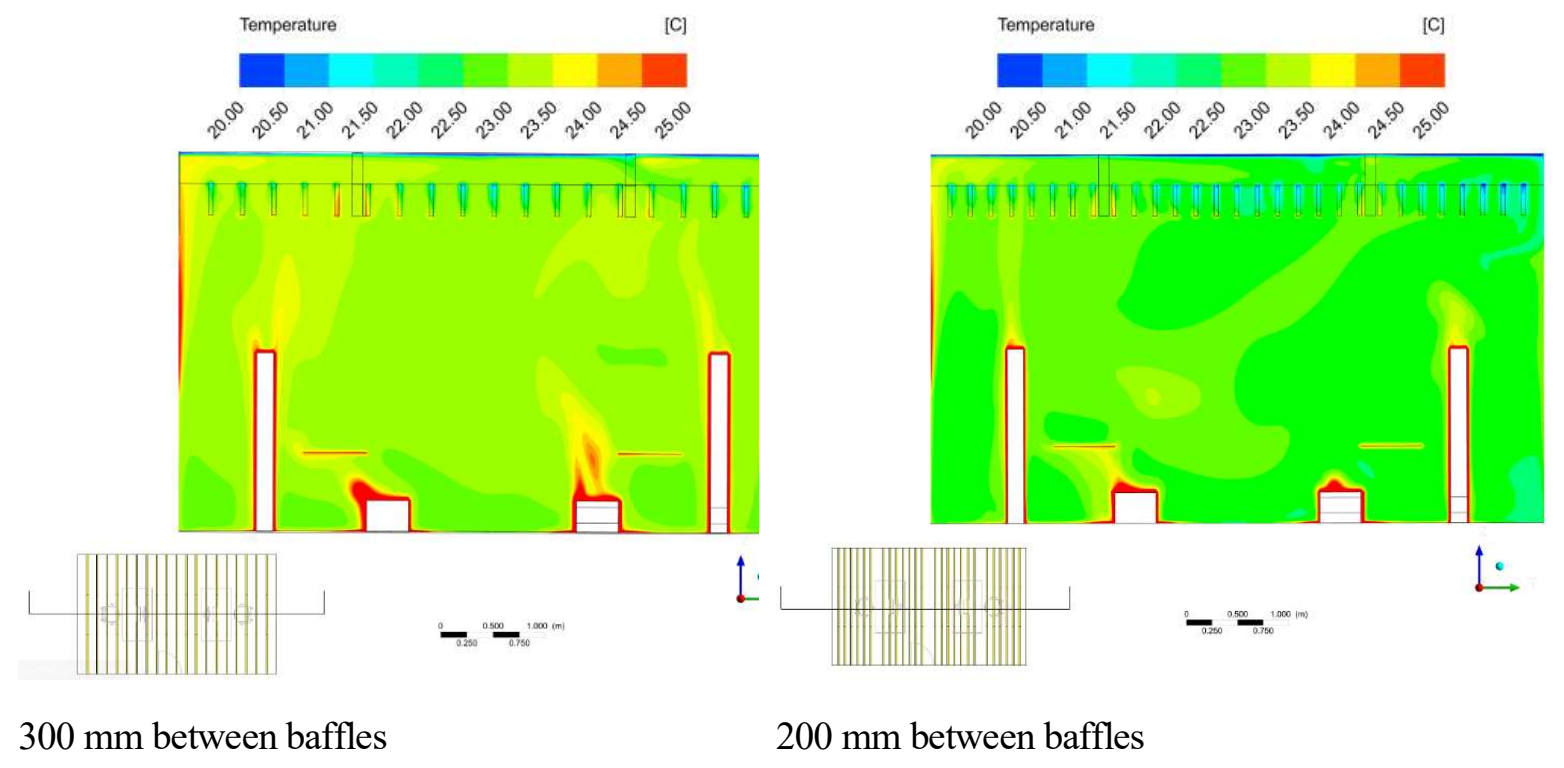

Figure 13: Comparison of air temperature distribution for different coverage ratios with vertical panels according to CFD simulations

\subsection{Comparison between horizontal and vertical panels}

Figure 14 shows a comparison of the measured operative temperature as a function of the Equivalent Absorption Area (EAA) in the octave bands $500 \mathrm{~Hz}$ and $1000 \mathrm{~Hz}$ provided by each scenario. As it can be observed, the temperature increase is very similar for horizontal and vertical panels for low coverage ratios (left part of the figure), whereas a difference of $0.5 \mathrm{~K}$ is found for the scenarios with equivalent sound absorption to that of 60 and $80 \%$ coverage. 


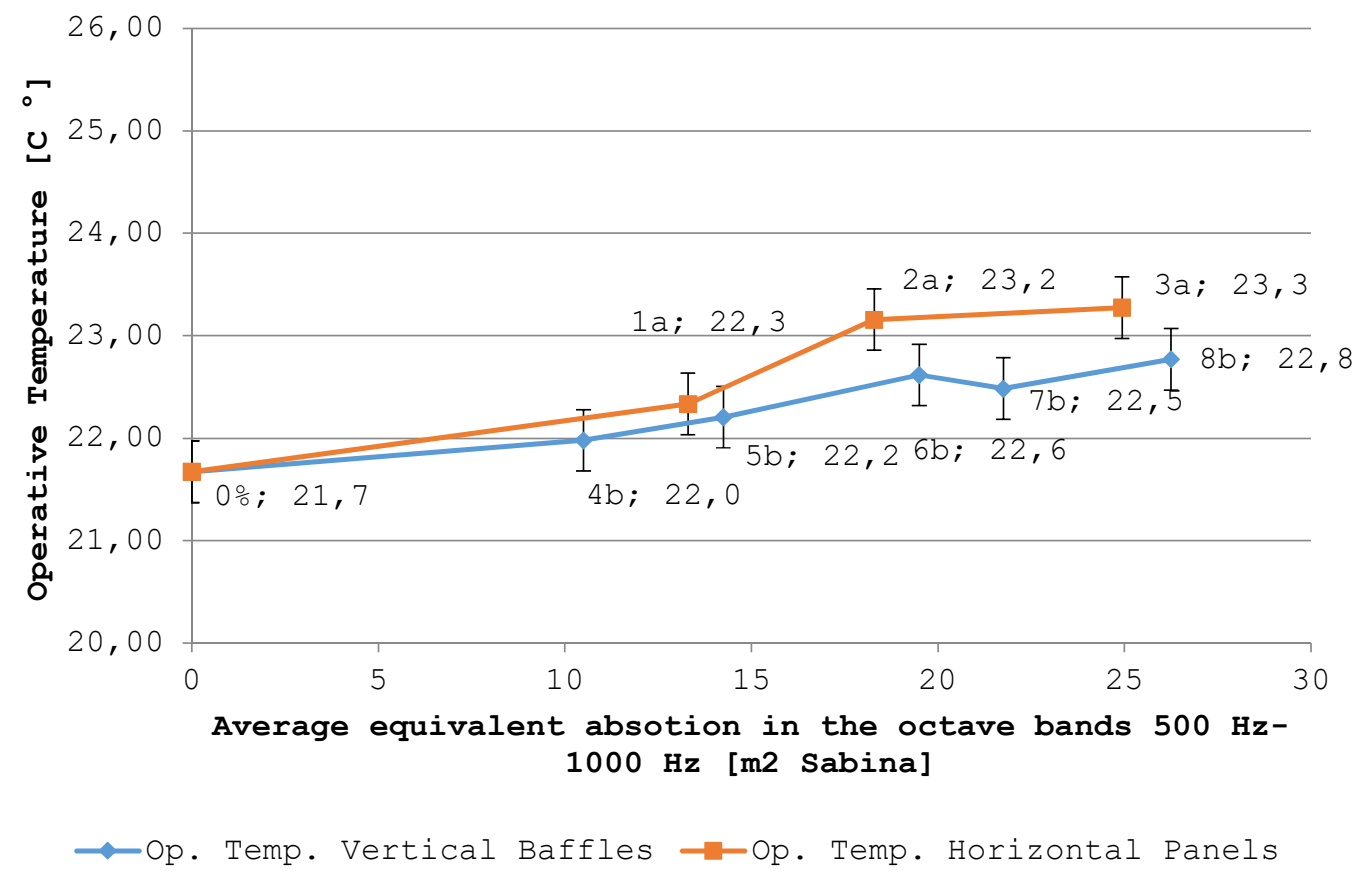

Figure 14: Comparison of operative temperature (measured at $0.6 \mathrm{~m}$ ) as a function of the Equivalent Absorption Area in the mid-frequencies

Figure 15 shows a comparison between the air temperature in the room (at $0.6 \mathrm{~m}$ from the floor) and that of the plenum as a function of Equivalent Absorption Area in the midfrequencies.

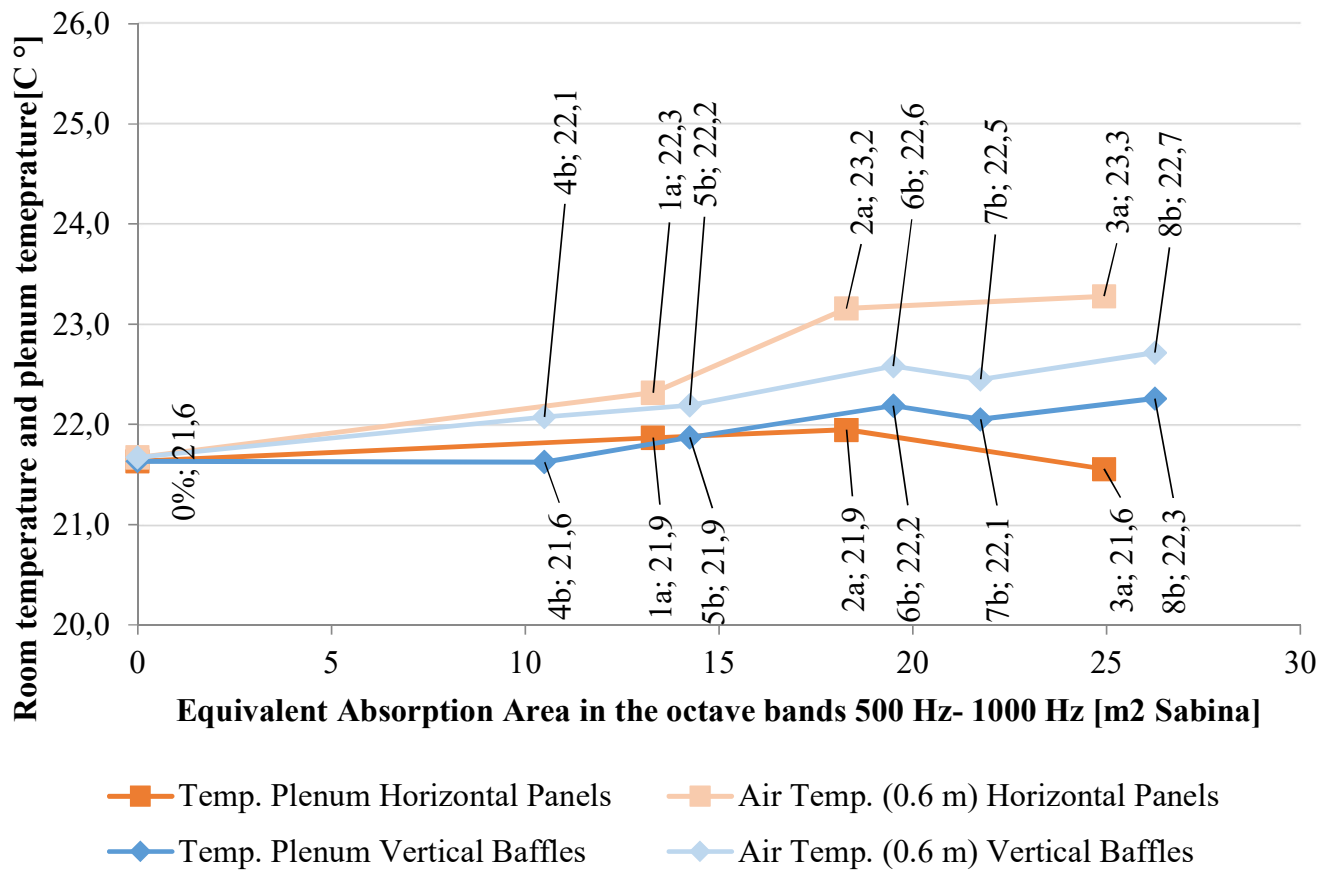




\section{Figure 15: Plenum and room temperature comparison of horizontal and vertical panels}

as a function of average equivalent absorption area in the octave bands $500 \mathrm{~Hz}-1000 \mathrm{~Hz}$

As it can be seen, the air temperature in the plenum increases proportionally to that in the occupied zone of the room in the scenarios with vertical panels, whereas in the case of the horizontal panels the temperature in the occupied zone increases with the increase of coverage ratio and the temperature in the plenum decreases. The temperature difference between the occupied zone of the room and the plenum has been measured to be $0.5 \mathrm{~K}$ for $43 \%$ coverage, $1.2 \mathrm{~K}$ for $60 \%$ coverage and $1.7 \mathrm{~K}$ for $80 \%$ coverage. In the case of the baffles, the temperature difference between room and plenum is in the range of 0.3 to $0.4 \mathrm{~K}$.

Based on acoustic recommendations [31], covering $60 \%$ of the ceiling surface with freehanging horizontal sound absorbers will provide the sound absorption needed to keep a comfortable acoustic environment in offices. Considering this ceiling coverage ratio, an operative temperature increase of $1.6 \mathrm{~K}$ could be expected according to the measurements performed. Free-hanging vertical sound absorbers have a lower impact on the operative temperature than horizontal ones for equivalent sound absorption levels. From the acoustic point of view, vertical sound absorbers with a spacing between panels of $200 \mathrm{~mm}$ represent an optimal solution [31]. According to the measurements performed, the operative temperature will increase $0.8 \mathrm{~K}$ when the ceiling is covered with vertical sound absorbers with a spacing of $200 \mathrm{~mm}$.

\section{Conclusion}

Thermally Activated Building Systems (TABS) buildings require a well-balanced acoustic design in order to provide the occupants an optimal comfort level. Covering the ceiling surface of the TABS with acoustic panels will lead to an increase of the operative temperature of the room due to heat exchange impediment created by the panels. This does not necessarily mean that free hanging sound absorbers should be avoided. In fact, modern buildings with large open spaces require the use of ceiling suspended acoustic units since wall-mounted units only are not sufficient to meet the acoustic requirements [29]. In this study, two kinds of free hanging sound absorbers have been tested, i.e. horizontal panels and suspended baffles. The sound absorbers block (at least partially) the heat exchange between the TABS and the room, leading to a decrease in the cooling performance of the TABS. The cooling performance decrease has an impact on the operative temperature of the room. In the case of horizontal sound absorbers, the operative temperature increase has been measured to be $0.5 \mathrm{~K}$ for $43 \%$ coverage ratio and $1.2 \mathrm{~K}$ for $60 \%$ coverage compared to a reference case without any sound absorbers. The increase of operative temperature in the scenarios with baffles is less prominent for equivalent sound absorption levels. An operative temperature increase of $0.8 \mathrm{~K}$ has been found for the highest coverage scenario.

Computational Fluid Dynamics (CFD) simulations have been used to illuminate the nature of the heat exchange between the TABS and the room and how the presence of free-hanging sound absorbers influences the heat exchange. Cold air stagnation in the plenum has been 
identified as the major threat for the convective heat exchange between the TABS and the room. The masking effect of the panels prevents stagnated cold air from mixing with the room air. Vertical sound absorbers with a spacing between panels of $200 \mathrm{~mm}$ represent an optimal solution both from the acoustic and thermal point of view, though this solution requires more absorptive material compared to horizontal panels for equivalent levels of sound absorption.

\section{Recommendations}

Further studies on new ventilation strategies in combination with TABS could help to illuminate solutions for this issue. The relative position between the heat loads and the horizontal panels has an effect on the heat exchange due to convection. Panels positioned directly above the occupants block the thermal plume generated by these latter ones. A recommendation would be to avoid the presence of horizontal panel directly above the occupants, or increase the space between panels in areas presumed to be occupied, i.e. working stations. The mentioned masking effect has not been observed in the scenarios with baffles, hence it can be concluded that baffles recessed from the soffit do not have a measurable effect on the heat exchange due to convection.

\section{References}

[1] European Environment Agency (EEA), "End-user GHG emissions from energy. Reallocation of emissions from energy industries to end users 2005-2010,” 2012.

[2] J. Babiak, B. W. Olesen and D. Petráš, Low temperature heating and high temperature cooling, Brussels: REHVA - Federation of European Heating, Ventilation and Air Conditioning Associations, 2009.

[3] R. A. Meierhans, "Room air conditioning by means of overnight cooling of the concrete ceiling," ASHRAE Transactions, V. 102, Pt. 1, pp. 693-697, 1996.

[4] B. W. Olesen, "Low temperature heating and high temperature cooling of buildings using hydronic surface systems," in Proceedings of Healthy Buildings 2000, Vol. 2, Espoo, 2000.

[5] B. W. Olesen, "Using Building Mass To Heat and Cool," ASHRAE Journal, vol. 54, no. 2, pp. 44-52, 2012.

[6] O. B. Kazanci, "Low temperature heating and high temperature cooling in buildings, PhD Thesis," Technical University of Denmark, Kgs. Lyngby, 2016.

[7] H. E. Feustel and C. Stetiu, "Hydronic radiant cooling - preliminary assessment," Energy and Buildings, vol. 22, pp. 193-205, 1995.

[8] B. Olesen, "Radiant Floor Cooling Systems," ASHRAE Journal, vol. 50, no. 9, pp. 16$22,2008$. 
[9] O. B. Kazanci, M. Shukuya and B. W. Olesen, "Theoretical analysis of the performance of different cooling strategies with the concept of cool exergy," Building and Environment, no. 100, pp. 102-113, 2016.

[10] R. A. Meierhans, "Slab cooling and earth coupling," ASHRAE Transactions, V. 99, Pt. 2, pp. 511-518, 1993.

[11] B. Lehmann, V. Dorer and M. Koschenz, "Application range of thermally activated building systems tabs," Energy and Buildings, vol. 39, pp. 593-598, 2007.

[12] C. Stetiu, "Energy and peak power savings potential of radiant cooling systems in US commercial buildings," Energy and Buildings, vol. 30, pp. 127-138, 1999.

[13] M. d. Carli, "New Technologies in radiant Heating and Cooling," Padova, 2002.

[14] K.-N. Rhee, B. W. Olesen and K. W. Kim, "Ten questions about radiant heating and cooling systems," Building and Environment, vol. 112, p. 367-381, 2017.

[15] S. Banbury, "Disruption of Office-Related Tasks by Speech and Office Noise," British Journal of Psychology, 89 (3), 499-517, 1998.

[16] R. T. Muehleisen, “Acoustics of green buildings,” Implications 8.1 , 2010.

[17] E. Pittarello, "Influence of acoustical panels on cooling of thermo-active-buildingsystems (TABS)," Technical University of Denmark, Kgs. Lyngby, 2007.

[18] P. Weitzmann, E. Pittarello and B. W. Olesen, "The cooling capacity of the Thermo Active Building System combined with acoustic ceiling," in Proceedings of the 8th symposium on Building Physics in the Nordic Countries, Copenhagen, 2008.

[19] H. Peperkamp and M. Vercammen, "Thermally activated concrete slabs and suspended ceilings," in Proceedings of NAG/DAGA 2009 International Conference on Acoustics, Rotterdam, 2009.

[20] M. L. Vercammen, "Concrete core activation and suspended ceilings: Designing for comfort, energy efficiency and good acoustics," in Proceedings of Healthy Buildings Europe 2015, Eindhoven, 2015.

[21] S. Ruud, "Testing of acoustic ceiling boards' influence on cooling capacity," SP Technical Research Institute of Sweden, Borås, 2008.

[22] Peutz, "Ecophon ceiling panels in relation to Thermally Activated Building Systems (TABS) - Climatic chamber test, Report number DB 2805-2E-RA-001," Peutz BV, Mook, 2013.

[23] Y. L. Muet, H. Peperkamp and R. Machner, "Combining thermally activated cooling technology (TABS) and high acoustic demand: Acoustic and thermal results from field measurements," in Proceedings of Inter-Noise 2013, the 42nd International Congress and Exposition on Noise Control Engineering, Innsbruck, 2013. 
[24] Y. L. Muet and P. Lombard, "Combining thermally activated cooling technology (TABS) and high acoustic demand: Acoustic and thermal results from field measurements part 2," in Proceedings of Euronoise 2015, the 10th European Congress and Exposition on Noise Control Engineering, Maastricht, 2015.

[25] R. Machner, "Thermal comfort in office buildings in line with a new German acoustic guideline," Energy Procedia - 6th International Building Physics Conference, IBPC 2015, vol. 78, pp. 2881-2886, 2015.

[26] H. Drotleff, R. Wack, P. Leistner, A. Holm, M. Ziegler and K. SedlBauer, "Integrated sound absorption in thermally activated concrete ceilings - acoustic and thermal effectiveness of sound-absorber strips spaced at intervals," Bauphysik, vol. 33, pp. 274286, 2011.

[27] P. Lombard, "Measure and model of free hanging sound absorbers impact on thermal comfort," in Proceedings of Eighth Windsor Conference: Counting the cost of comfort in a changing world, Cumberland Lodge, 2014.

[28] N. Rage, O. B. Kazanci and B. W. Olesen, "Validation of a numerical model of acoustic ceiling combined with TABS," in Proceedings of the 12th REHVA World Congress, CLIMA 2016, Aalborg, 2016.

[29] N. Rage, O. B. Kazanci and B. W. Olesen, "Numerical simulation of the effects of hanging sound absorbers on TABS cooling performance," in Proceedings of the 12th REHVA World Congress, CLIMA 2016, Aalborg, 2016.

[30] N. Langner and D. Bewersdorff, "Thermal and acoustical simulation of open space working areas in commercial buildings equipped with thermally activated building systems," in Proceedings of BS2015: 14th Conference of International Building Performance Simulation Association, Hyderabad, 2015.

[31] Ecophon, "Knowledge Guide. Sound absorption - free-hanging units vs. full ceiling," Ecophon, Hyllinge, 2015.

[32] Ecophon, "Ecophon Master MatrixTM Technical Datasheet," Ecophon, Hyllinge, 2015.

[33] L. M. Domínguez, "Influence of Acoustic Ceiling Units on the Cooling Performance of Thermo-Active Building Systems (TABS)," Technical University of Denmark, Kgs. Lyngby, 2016.

[34] G. K. Pavlov, "Building thermal energy storage, PhD Thesis," Technical University of Denmark, Kgs. Lyngby, 2014.

[35] EN ISO 7726, "Ergonomics of the thermal environment - Instruments for measuring physical quantities," European Committee for Standardization, Brussels, 2001. 
[36] A. Simone, B. W. Olesen, J. L. Stoops and A. W. Watkins, "Thermal comfort in commercial kitchens (RP-1469): Procedure and physical measurements (Part 1)," HVAC\&R Research, pp. 1001-1015, 2013.

[37] Ansys Inc., “ANSYS Fluent UDF Manual, 15317(November), 724-746,” 2009.

[38] Ansys Inc., "Meshing Help. Portal, 15317,” 2009.

[39] ISO/IEC Guide 98-3:2008, "Uncertainty of measurement - Part 3: Guide to the expression of uncertainty in measurement (GUM:1995)," International Organization for Standardization, Geneva, 2008. 